\title{
Study of $R$-molar ratio effect on the transformation of tetraethylorthosilicat precursor to gels in sol-gel technique
}

\author{
Wesam A. A. Twej* Firas J. Al-maliki* Baha T. Chiad *
}

Date of acceptance 3/3/2009

\begin{abstract}
The effect of using different $R$-molar ratio under variable reaction conditions (acidic as well as basic environment and reaction temperature) have been studied. The overall experiments are driven with open and closed systems. The study shows that there is an optimum value for a minimum gelling time at $R$ equal 2 . The gelling time for all studied open system found to be shorter than in closed system. In acidic environment and when $R$ value increased from 2 to 10 , the gelling time of closed systems has increased four times than open systems at $\mathrm{T}=30{ }^{\circ} \mathrm{C}$ and fourteen times when temperature reaction increased to $60{ }^{\circ} \mathrm{C}$. While in basic environment the influence of increasing $\mathcal{R}$ value was limited.
\end{abstract}

Key words: Sol-Gel, TEOS, $\mathrm{R}$-molar ratio

\section{Introduction}

The sol-gel process involves the production of a suspension of a solid in liquid, followed by the removal of the liquid, and finally densification of the solid. It has the advantages of low processor temperatures, mixing at the molecular level to produce hybrid systems, and fabrication of novel materials like highly homogenous glasses, ceramics, and composites [15].

$$
\begin{aligned}
& (\mathrm{OR})_{3}-\mathrm{Si}-(\mathrm{OR})+\mathrm{H}_{2} \mathrm{O} \underset{\text { Re-estrification }}{\stackrel{\text { Hydrolysis }}{\rightleftarrows}}(\mathrm{OR})_{3}-\mathrm{Si}-(\mathrm{OH})+\mathrm{ROH}----(\mathbf{1}) \\
& (\mathrm{OR})_{3}-\mathrm{Si}-(\mathrm{OH})+(\mathrm{OR})_{3}-\mathrm{Si}-(\mathrm{OH}) \underset{\text { Wydrolysis }}{\stackrel{\text { Water condensation }}{\rightleftarrows}}(\mathrm{OR})_{3}-\mathrm{Si}-\mathrm{O}-\mathrm{Si}-(\mathrm{OR})_{3}+\mathrm{H}_{2} \mathrm{O}---(2) \\
& (\mathrm{OR})_{3}-\mathrm{Si}-(\mathrm{OH})+(\mathrm{OR})_{3}-\mathrm{Si}-(\mathrm{OR}) \underset{\text { Alcoholysis }}{\stackrel{\text { Alcohol condensation }}{\rightleftarrows}}(\mathrm{OR})_{3}-\mathrm{Si}-\mathrm{O}-\mathrm{Si}-(\mathrm{OR})_{3}+\mathrm{ROH}---(3),
\end{aligned}
$$

Where; $\mathrm{R}$ is an alkyl group such as ethyl reagent $\left(\mathrm{C}_{2} \mathrm{H}_{5}\right)$ in TEOS precursor. The formation of the sol (i.e. a colloidal suspension in a liquid of hydrolysis reaction of TEOS precursor. While the colloidal particles and condensed silica species linked together to become a 3-D gel network (i.e. a continuous solid structure that *Department of Physics, College of Science, University of Baghdad, 
contains a continuous liquid phase). The reaction from TEOS solution to a solid material is not simple one and many parameters are possible. These parameters involve: $R$-molar ratio $\left(\mathrm{H}_{2} \mathrm{O}\right.$ :TEOS), and catalyst type which involves $\mathrm{pH}$ value of solution, that have major effects on the reactions rate, and subsequently on the characteristics of a silica gel network, reaching the final products. The water content of the silicon alkoxide solution markedly affects the structure and properties of the siloxane particles ( $\mathrm{Si}$ $\mathrm{O}-\mathrm{Si}$ ) produced in the sol.

In this study, we will focus on the water content factor ( $R$-ratio), and its activity on the rate of reactions, gelling time, and the bulk gel nature. Where it was known that the $R$ values ranging from stoichiometric ratio to high values, depending on the desired polysilicat product.

\section{Materials and Methods}

Using sol-gel technique the gel samples were prepared. Firstly two solutions (for each study samples) were prepared: silica solution containing $1 \mathrm{ml}$ of (TEOS) (Purity> $98 \%$ supplied by Schuchardt, Hohenbrunn, Germany, and $2 \mathrm{ml}$ of ethanol Analytical grade. (Purity
$99.9 \%$ ) supplied by Gainland Chemical Company, U.K. And catalyst solution containing $2 \mathrm{ml}$ of pure ethanol and $\mathrm{X}$ $\mathrm{ml}$ of Deionized water at $\mathrm{pH}$ values: 4 , 7, 9; using $\mathrm{HCl}$ acid $(0.15 \mathrm{M} \mathrm{HCl} 37 \%)$ supplied by Aldrich $\mathrm{Co}$.; and $\mathrm{NH}_{3}$ base supplied by $\mathrm{BDH}$ limited, Poole, England. Where $\mathrm{X}=1.4$ to 10 , corresponding to $R$-molar ratio: from 1.4 to 10 . The catalyst solution was slowly added to the silica solution with magnetic stirring for one hour. The resultant sol was poured into cylindrical glass containers. Immediately after the chemicals are mixed, the recipes were divided into two parts; the first one is kept without any cover while the other one under tightly sealed cover molds, the overall samples kept at fixed reaction temperatures $30^{\circ} \mathrm{C}, 40{ }^{\circ} \mathrm{C}, 60{ }^{\circ} \mathrm{C}$ for (72 hour) until tetraethylorthosilicat precursor transform to gels. Because of immiscibility of TEOS with water, a mutual solvent such as ethyl alcohol is added. While Formaldehyde, supplied by $\mathrm{BDH}$ limited, Poole, England; is added as drying control chemical additive

The following scheme shows the overall process of the recipes which is studied in this work:

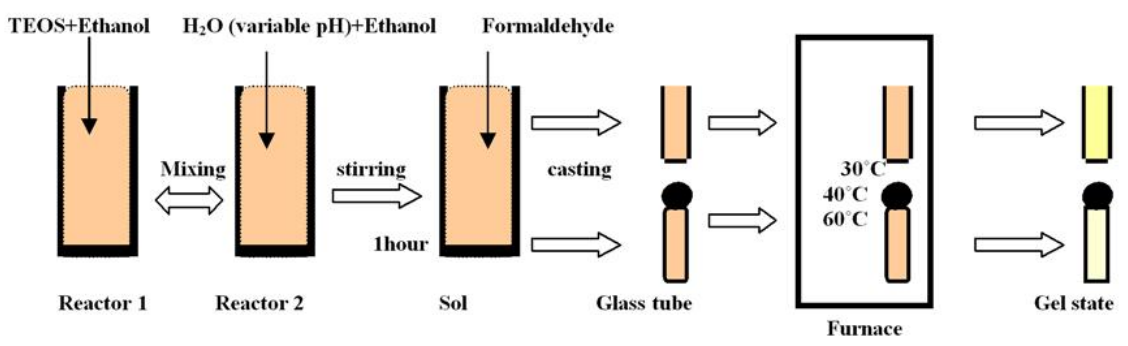

Figure (1): Gelation process of (TEOS- Ethanol-Water) system. 


\section{Results and discussion}

The precursor solutions which are prepared at molar ratio $R=2$ for all $\mathrm{pH}$ values and reaction temperatures, takes minimum time to reach a gel state (i.e. gelling time), as shown in figure (2) and subsequently figures (3 a-d). In order to explain this behavior, it was known that $R$ value of 2 is theoretically sufficient for complete hydrolysis and condensation reactions [8-10]. Equation (1) at $R=2$ can be written as follows:

$2 \mathrm{Si}(\mathrm{OR})_{4}+4 \mathrm{H}_{2} \mathrm{O} \rightarrow 2\left[(\mathrm{HO})_{2}-\mathrm{Si}-(\mathrm{OR})_{2}\right]+4 \mathrm{ROH}---(4)$

Here we have an equivalent numbers of $(\mathrm{OH})$ and $(\mathrm{OR})$ groups on the silicon atom in each monomer, producing a partially hydrolyzed molecules and needing a half time for hydrolysis reaction. Thus alcohol producing condensation here is favored. This equivalence between the two types of groups (i.e. $\mathrm{OH}$ and $\mathrm{OR}$ on $\mathrm{Si}$ atom) will be accelerated the formation and aggregation of the condensed species. So the speed of cross-linking of siloxane particles will be increased. Therefore, we have equilibrium in the rate of hydrolysis and condensation reactions, which yield minimum gelling time[11].

While at stoichiometric ratio ( $R=1.4$ ), the gelation process of the prepared solutions have gelling time longer than at in the case of $(R=2)$ as shown in figures $(2,3)$. This may be attributed to the slow hydrolysis rate, where the monomers of TEOS precursor have not chemically equivalent amount of water molecules required to complete the hydrolysis

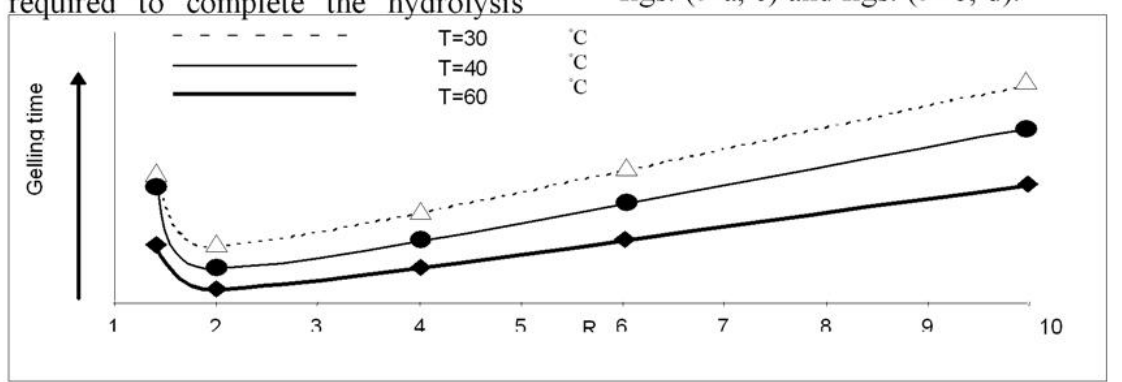

Figure (2): Gelling time as a function of R-ratio at three temperatures. 592 reaction, and leads to delay the condensation process.

However, in excess water recipes $(R=10)$, the hydrolysis reaction will promote by increasing the number of sites to be hydrolyzed. Therefore, the water producing condensation will be favored here. Although, since water is the by-product of condensation reaction (Eq. 2). So it retards the condensation reactions and caused more completion to the hydrolysis of monomers before significant condensation occurs (reveres of Eq 2) [12]. The high excess in water ratio will reduce the probability of primary aggregation between the silanol groups $\mathrm{Si}(\mathrm{OH})$, resulting in a long gelling time as shown in figures $(2,3)$.

\section{Open and closed systems effect}

However alcohol is more evaporate than water at the studied temperatures in open system. So that the probability of re-estrification reaction (reverse of eq.(1) will be decreased leading to enhanced the hydrolysis rate. On the other hand, the quantity of alcohol and water remain approximately constant under tightly sealed molds. The closed system prevents the evaporation of alcohol and water. Therefore the reverse reaction of Eq. (1) is prompt and the hydrolysis rate will be decreases and subsequently the condensation rate. So the gelling time for all the closed system recipes at all $\mathrm{pH}$ values and reaction temperatures are longer than its value for open system recipes as shown in figs. $(3-a, c)$ and figs. (3-b, d). 
The present study shows that there is a noticeable effect of the reaction temperature on the gelling time when $R$ -ratio increased from 2 to 10 . This affection is obviously clear in acidic solutions (i.e. $\mathrm{pH} \mathrm{4}$ ), and little in basic solutions (i.e. $\mathrm{pH} 9$ ).

Assuming that $\left(\delta_{\tau}\right)$ is the ratio of the gelling time at $(R=10)$ to its value at $(R=2)$. In the case for acidic solution; the results of open system recipes show that $\left(\delta_{\tau}=4\right)$ at $\mathrm{T}=30{ }^{\circ} \mathrm{C}$, and $\left(\delta_{\tau}=14\right)$ at $\mathrm{T}=60{ }^{\circ} \mathrm{C}$. This means that the gelling time is increased four times at $\mathrm{T}=30{ }^{\circ} \mathrm{C}$ and fourteen times when temperature reaction increased to $60{ }^{\circ} \mathrm{C}$ as shown in figures (3: a, b). These results may be explained as follows:

Iler [11] confirmed that an increasing in temperature reaction leads to further growth of silica particles in size, and therefore decreases in number. Also when the reaction temperature increased the particles kinetic energy will be increases too. Thus the probability of collision (aggregation and crosslinking) will be increased resulting in short gelling time.

While for closed system recipes, also in acidic solutions, where $\left(\delta_{\tau}=1.3\right)$ at $\mathrm{T}=30{ }^{\circ} \mathrm{C}$, and $\left(\delta_{\tau}=4.8\right)$ at $\mathrm{T}=60{ }^{\circ} \mathrm{C}$, comparing with there values of open system recipes, the value of $\delta_{\tau}$ will be decreased, in general, three times of its values in open system. This may be attributed to the same reasons mentioned before (i.e. the evaporation of water as well as alcohol which increase the probability of collision). Then the evaporation prevention in close system can act as the essential factor in reducing $\left(\delta_{\tau}\right)$ from 4 to 1.3 at $\mathrm{T}=30{ }^{\circ} \mathrm{C}$ and from 14 to 4.8 at $\mathrm{T}=60{ }^{\circ} \mathrm{C}$ in open system. This may enhance the explanation of evaporation factor.
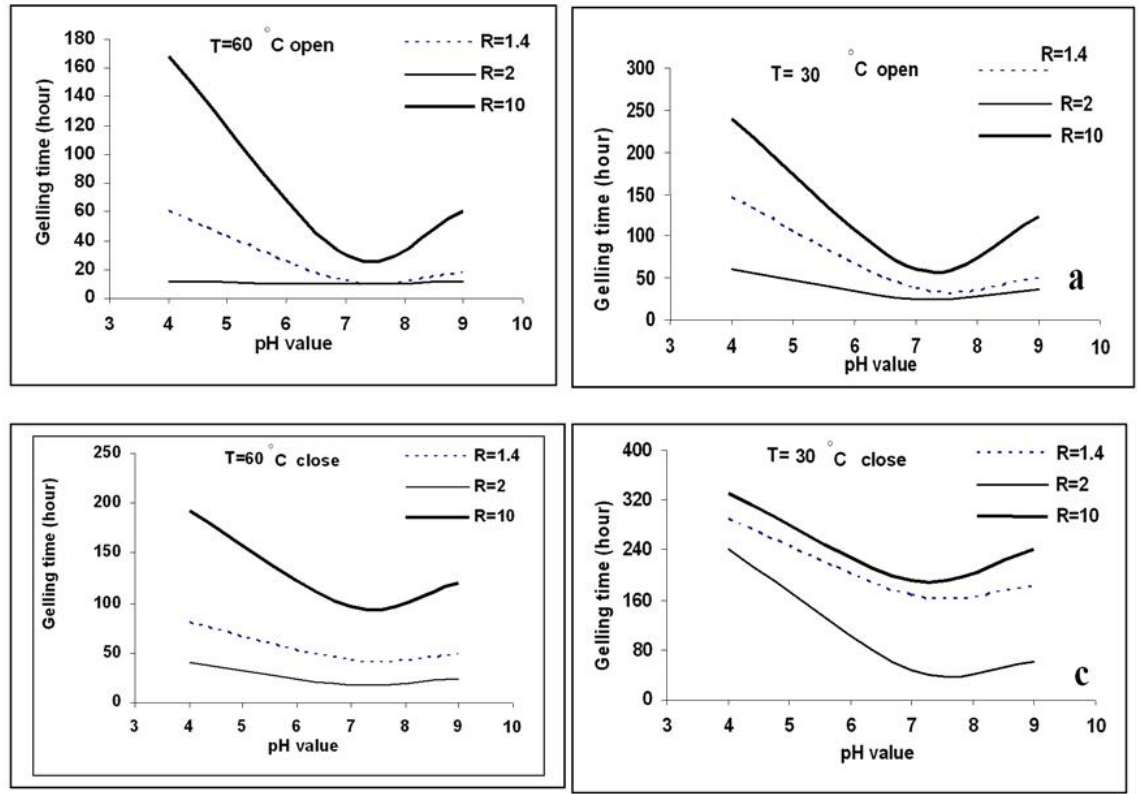

Figure (3): Gelling time as a function of $\mathrm{pH}$ at three $\mathrm{R}$-ratio values; $\mathrm{a}$. $\mathrm{T}=\mathbf{3 0 \mathrm { C }}$ open, $b$. $T=30^{\circ} \mathrm{C}$ close, $c$. $T=60^{\circ} \mathrm{C}$ open, $d . T=60^{\circ} \mathrm{C}$ close. 
Regarding to the figures $(3-a, c)$ and figures $(3-b, d)$, the effect of removing the sealed cover from the mold of the recipes driven at $R=2$ and $\mathrm{T}=30^{\circ} \mathrm{C}$ is very clear compared with the case of $\mathrm{T}=60{ }^{\circ} \mathrm{C}$. However alcohol is cosolvent in sol-gel process (i.e. dose not chemically react with the precursor in hydrolyses and condensation) [1], but its excess amount will prevent the particles collision leading to retardation of the cross-linking and gelation process. At $\mathrm{T}=30^{\circ} \mathrm{C}$; the rate of water evaporation is very little and can be negligible compared with alcohol evaporation. In this case the sol in the open system will suffer from alcohol evaporation only, resulting in faster gelling time. While at $\mathrm{T}=60^{\circ} \mathrm{C}$ the effect of primary growth of particles with temperature dominates.

\section{Conclusion}

Regardless of increasing the reaction temperature, which enhances the gelation process, and starting from stoichiometric $R$ ratio, for both open and closed systems, the gelation process is promoted and then the gelling time is reduced reaching a minimum value at $R$ equal 2 . Then the gelling time increases monotonically with further increase of $R$ value. In acidic environment, as $R$ ratio increases more than 2 the gelling time will increase dramatically, while there are little influences in basic environment.

\section{References}

1. Brinker, C.J. and Scherer, G.W. 1990, The physics and chemistry of sol-gel processing , Academic Press Inc., San Diego, 4,599.

2. Gutzov, S., Ahmad, G., Petkova, N., Fuglein, E., Petkov, I., preparation and optical properties of samarium doped sol-gel materials, 2008. Journal of noncrystalline solids354,3438-3442.
3. Kirkbir, F., Murala, H., Mayers, D., Chauthari, S. R. and Sarker, A. 1996 .Drying and sintering of solgel derived large $\mathrm{SiO}_{2}$ monoliths. Journal of sol-gel science technology, 6(11),203-207.

4. Scott, B. J., Wirnsberger, G. and Stucky, G. D. 2001. Mesoporous and Mesostructured Materials for Optical Applications. Chem. Mater., 13: 3140-3150.

5. Al-Wattar A. J., Chiad B. T., Twej W. A. A. and Al- Awadi S. S. 2006. Development of temporal spectroscopic properties or Xerogel matrices doped with Rhodamine $6 \mathrm{G}$ dye, Central European journal of physics, 4(3), 341-348.

6. Brinker, C. J., Hurd, A. J. and Ward, N. K. J. [in:] 1984 "Ultrastructure Processing of Advanced Ceramics. Mackenzie, Ulrich, J. D. D. R. (Eds.) John Wiley and Sons, CH. 15, pp. 223-240.

7. Suratwala,T.I. Hanna, M.L. Miller, E.L. Whitman, P.K. Thomas, I.M. Ehrmann, P.R. Maxwell, and Burnham A.K. 2003, Surface chemistry and trimethylsilyl functionalization of Stober silica sols, Journal of Non-Crystalline Solids, 19(5), 951-957.

8. Sun, S. F. 2004. Physical Chemistry of Macromolecules. 2nd ed., John Wiley \& Sons, Inc.

9. Campero, A. and Arroyo, R. 1988. Chemical modification of TEOS with acetic acid. Department of Chemistry, Universidad Autonoma Metropolitana, Mexico City, Part 2, Sol-Gel science\& technology.

10. Mccarthy, D.W. . Mark, J.E and Schaefer, D. W. 1998. Synthesis, structure, and properties of hybrid organic-inorganic based on polysiloxanes. I. poly (dimethylsiloxane) elastomers containing silica. Journal of 
polymer science: part B: polymer physics, 36: 1167-1189.

11. Iler R.K., 1979. The chemistry of silica. John Wiley and Sons, New York, 10,645.
12. Hakka, S. Kozuka,H. and. Kim S. $\mathrm{H}$ 1984. in: Ultrastructure Processing of Advanced Ceramics, Mackenzie, J. D. and Ulrich D. R. (Eds.), Chapter 10, pp. 159-171.

\section{دراسة تأثير النسبة المولارية R على تحول محلول مادة التتراثيل اورثو سيكات الى حائة الجيل في تقانة السول - جيل ماديل}

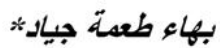

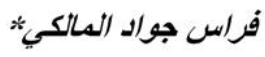

*قسم الفيزياء،كلية العلوم ،جامعة بغداد

الخلاصة

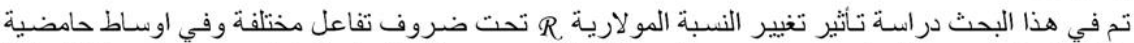

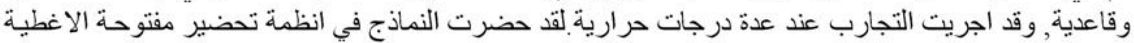

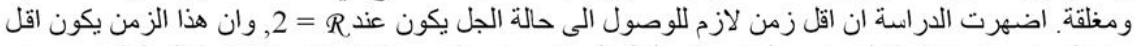

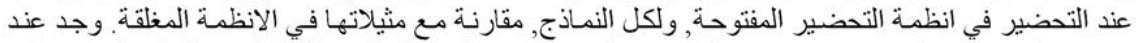

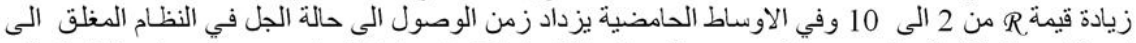

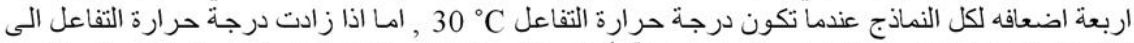

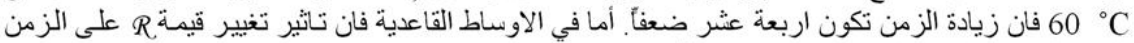

اللازم للوصول الى حالة الجل يكون محدوداً. 